Review Paper

\title{
Valves and actuator integrity and blast load calculations
}

\author{
Karan Sotoodeh ${ }^{1}$ \\ ๑) Springer Nature Switzerland AG 2019
}

\begin{abstract}
The mounting kit for a valve consists of a coupling, drive keys, dowel pin, and bolting hardware. The design of a mounting kit should be stress-based or based on previous experience and validation testing. The mounting kit is the most important section for providing valve and actuator integrity, so it should be capable of withstanding loads from actuator, wind, snow, seismic, and blast. Parameters such as type of valve and actuator and orientation, frequency of actuator cycling and speed of operation, coupling connections, adapter fabrication, and material of coupling can affect the strength of the coupling. This paper presents an example where improper machining of the drive shaft jeopardizes the integrity between the valve and actuator. Mismatch between machined parts of the stem inside bracket and coupling makes the stem not to be aligned correctly in the vertical position. Additionally, this paper discusses the integrity between a $6 " \times 4$ " ball valve in $22 \mathrm{Cr}$ duplex material and class 300 and the pneumatic actuator on this valve against longitudinal and shear stresses created by blast and internal pressure. Both shear and longitudinal stresses are less than $90 \%$ of the bolting yield stress for $22 \mathrm{Cr}$ duplex, so the conclusion is that the connections between the 6 " $\times 4$ " Class 300 ball valve and the pneumatic actuator are strong enough against blast loads.
\end{abstract}

Keywords Blast load $\cdot$ Valve and actuator integrity $\cdot$ Calculations $\cdot$ Oil and gas industry

\section{Introduction}

The mechanical integrity between the valve and actuator for valves manufactured under ISO 14313 and API 6D specifications is defined in API 6DX and ISO 12490 standards $[1,2]$. API 6 D specification defines the requirements for design, manufacturing, assembly, testing, and documentation of ball, check, gate, and plug valves for applications used in pipeline and piping for the petroleum and natural gas industries [3]. Similarly, ISO 14313 [4] has been developed with a scope that is very similar to API 6D. The driven component, including the drive adapter or drive shaft that allows transmission of torque and/or thrust from an actuator driving component to the valve shaft/stem, is called the coupling [1]. The actuator is an electrically, pneumatically, or hydraulically powered device bolted or attached to a valve for the automatic purpose of the applying torque or thrust to open and close the valve [1]. Figure 1 shows a pneumatic actuated ball valve with a cylindrical adapter between the valve and the actuator. The adapter, also called a bracket, spool, or adapter flange, is an intermediate support that enables the attachment between the valve and the actuator $[1,2]$. The ball valve is used to start or stop of the fluid in the connected piping system.

\section{Mounting kit}

Valve components including coupling, drive keys, a dowel pin, and bolting are called a mounting kit. The design of a mounting kit should be stress-based or based on previous experience and validation testing [1,2]. The mounting kit is the most important section for providing valve and

$\triangle$ Karan Sotoodeh, karan_sqi@yahoo.com; karan.sotoodeh@bhge.com | ${ }^{1}$ Piping Engineering, Baker Hughes, a GE Company, Høvik, Norway.

SN Applied Sciences (2019) 1:599| https://doi.org/10.1007/s42452-019-0624-z

Received: 18 March 2019 / Accepted: 14 May 2019 / Published online: 18 May 2019 
Fig. 1 Pneumatic actuated ball valve

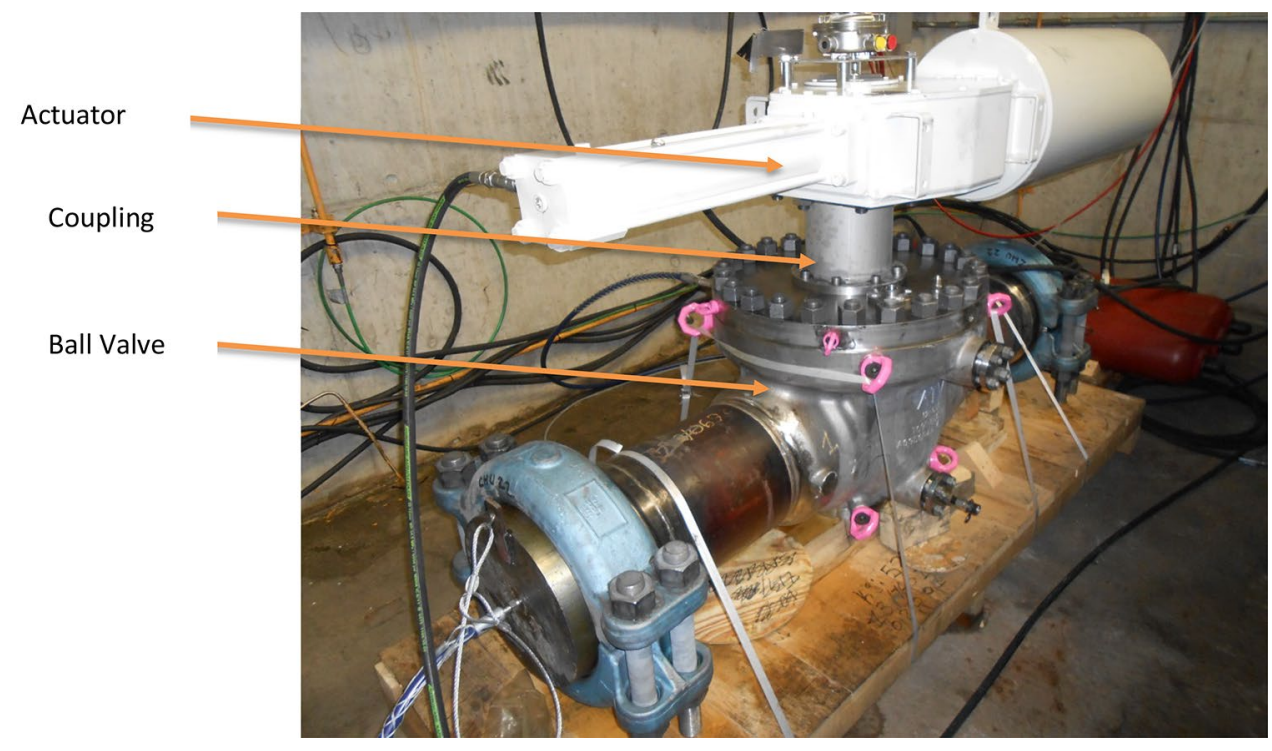

Fig. 2 Pressure safety valve on the control panel

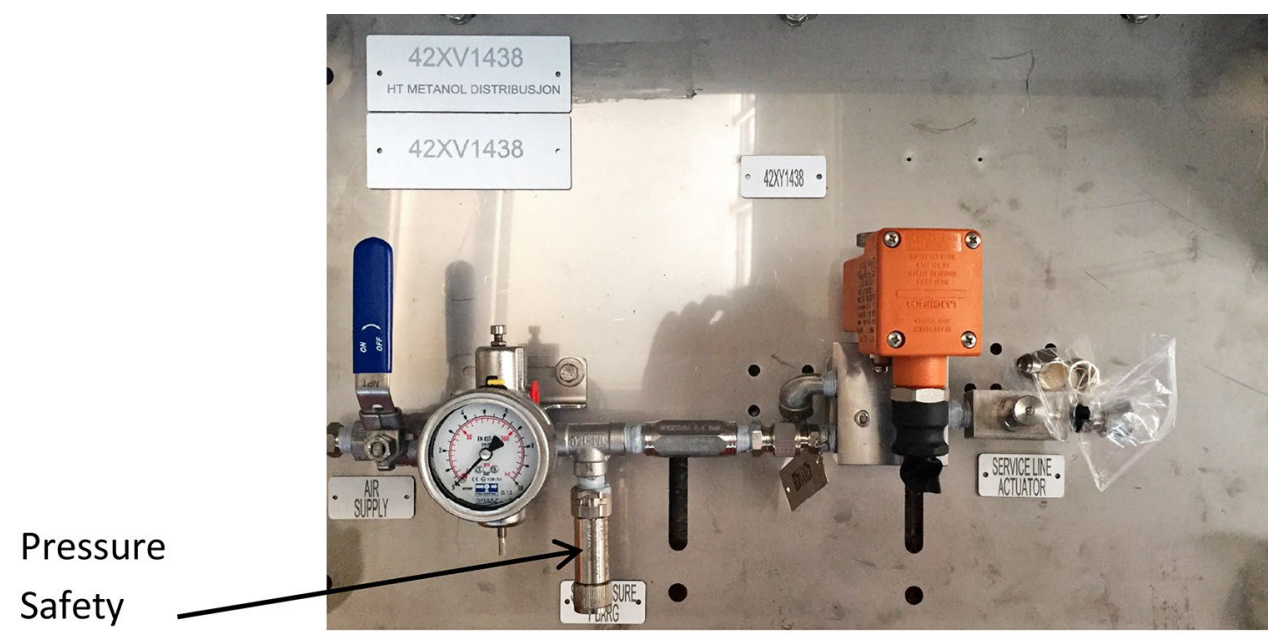

\section{Valve}

actuator integrity, so it should be capable of withstanding a variety of different loads and designed with consideration of the following parameters.

\subsection{Actuator loads}

A valve mounting kit should withstand 1.1 or more times the maximum torque or loads from the actuator to the valve $[1,2]$. The loads coming from the actuator include torque or thrust generated by a pressure safety valve on the control panel (Fig. 2), or by a spring in the spring return actuator (Fig. 3) or electrical actuator. It should be noted that pressure safety valves generate loads in the connecting piping or components during the operation due to releasing the pressure during the opening and spring load during the closure. Tensile stress in all parts of the mounting kit shall not exceed $67 \%$ of the yield strength while

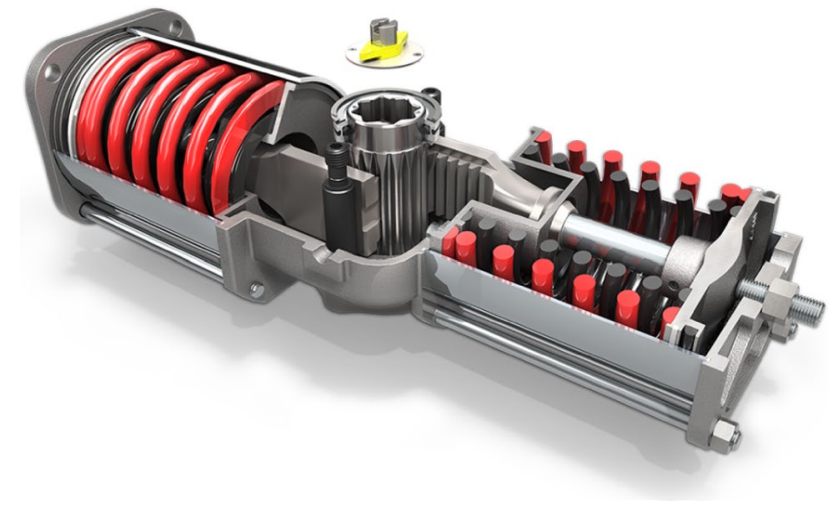

Fig. 3 Spring return actuator

\section{SN Applied Sciences}


delivering 1.1 or more times the maximum torque/thrust output $[1,2]$. Sizing an actuator depends on many parameters such as fluid differential pressure across the valve. Higher fluid pressure and pressure drop across the valve lead to larger actuator sizing and selection which increase the load on the coupling and valve stem.

\subsection{Other loads}

In addition to the actuator loads, the mounting kit should be designed based on the external loads due to environmental effects such as wind, snow, seismic and blasts [1, 2]. The blast or explosion load depends on the dynamic load and drag coefficient (pressure) [5]. Blast or explosion produces dynamic or drag loads that is represented by drag coefficient. The aim of this paper is to provide a calculation for checking the valve and actuator assembly against the external loads imposed by an explosion during the explosion, which will be explained in Sect. 3. Figure 4 shows a PDMS model with two actuated ball valves (blue) and a structure support (yellow and red). The reason for designing and applying the structure support is to protect the actuator from the blast load, since the blast load was not considered during the coupling design. It is recommended to have a gap between the support and actuator to provide enough space for passing the actuator air supply tubing through and maintaining the actuator flexibility.

\subsection{Valve and actuator orientation}

It is important to consider the orientation of the valve and actuator for the coupling design. Valve installed with a horizontal stem may require support $[1,2]$ between the

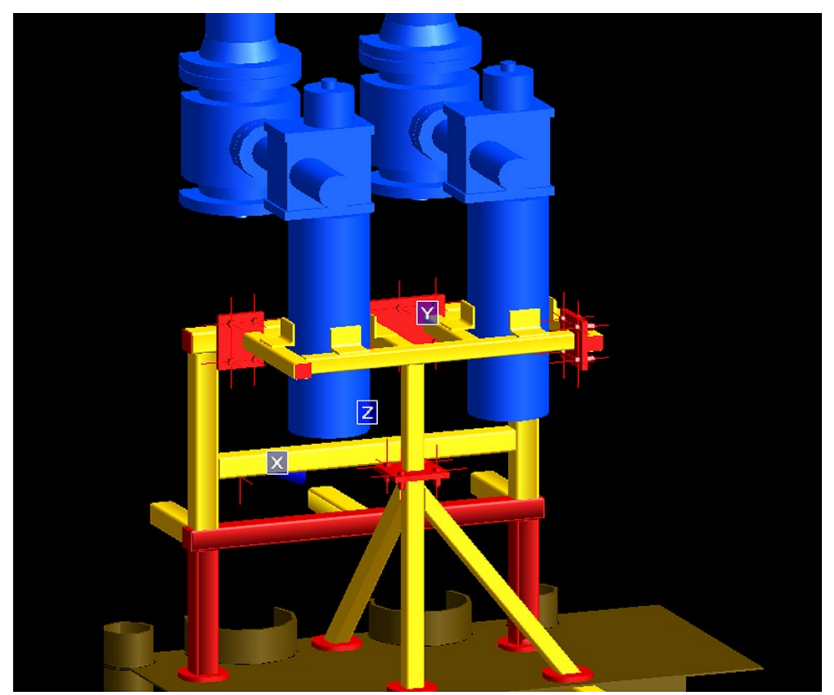

Fig. 4 Supported actuated valve against the blast load valve and the bottom of the actuator to ensure accurate alignment and integrity of the valve and actuator. In some cases, it is possible to increase the coupling bolt diameter or select a material with higher strength for coupling and bolting connections. The effect of actuator weight and orientation on the coupling has been experienced in hydraulic and pneumatic actuators.

\subsection{Frequency of cycling/speed of operation}

There is more stress on the actuator, valve, and coupling if the valve requires more cycling and/or a higher speed of operation. In fact, there is a limitation in using and cycling the actuators. As an example, some actuators should work for $25 \%$ of time which means that if the actuator runs for just $1 \mathrm{~min}$, it requires $3 \mathrm{~min}$ rest. Additionally, the speed of actuators should be within the limits have been specified by the end users based on process requirements. Fatigue analysis is a method widely used to evaluate the suitability of the actuator under dynamic loads due to high frequency of cycling or high speed operation. The fatigue analysis is normally done through simulation technology with motion to visualize the actuator movement and analyse possible failures and weak points of actuator during the life cycle. Higher actuator speed or cycling frequency requires designing more robust actuator (e.g. long-lasting bearing, shaft and internal sealing), and connected coupling through using higher strength and friction resistance materials. As an example, high cycle numbers of actuators during a qualification test to make sure that the actuator is capable of frequent operation could be a part of fatigue analysis.

\subsection{Type of valve and actuator orientation}

Unlike ball valves, an actuator is installed vertically on a through conduit gate valve (Fig. 5) or axial control valve. The vertically oriented actuator causes more load concentration on the mounted coupling and therefore may require a more robust coupling design and selection. However, no coupling may be required for electrically operated through conduit gate valves since the electrical actuator is light, as shown in Fig. 6.

\subsection{Coupling connections}

Dowel pins and bolting are parts of mounting kit connections are designed to transfer loads from the actuator to the valve. A dowel pin or fitted bolt ensures the proper location of the actuator. Misalignment or improper assembly of the actuator on the coupling can be prevented by suitable means such as a dowel pin or fitting bolt. A typical 


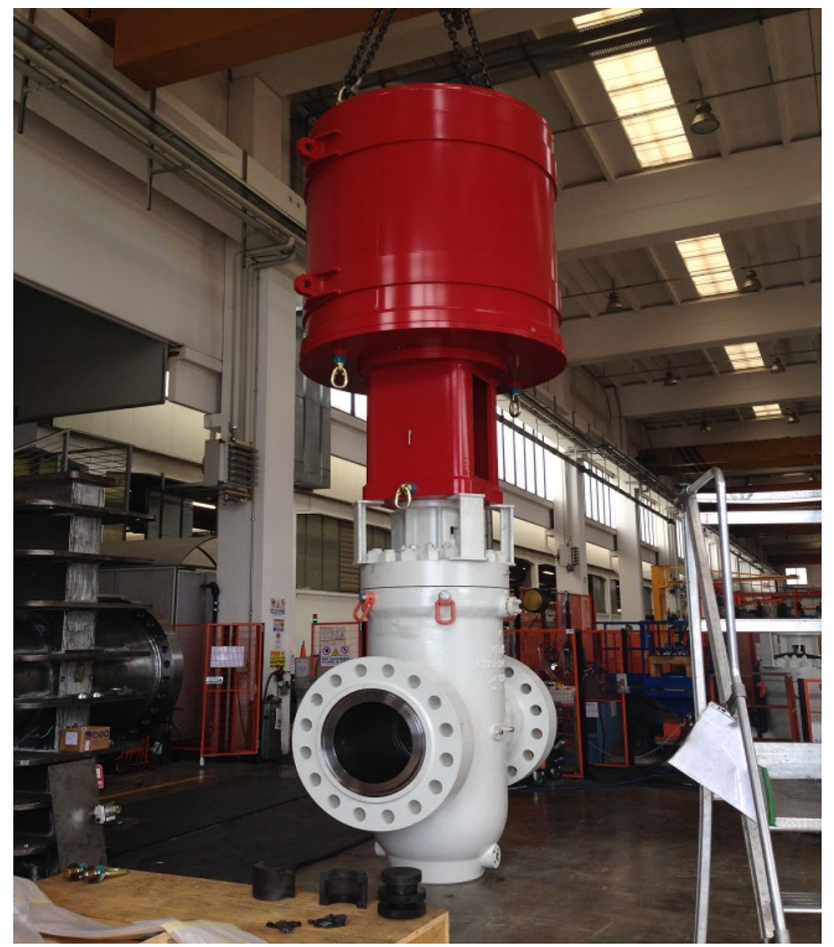

Fig. 5 Hydraulic actuator through conduit gate valve

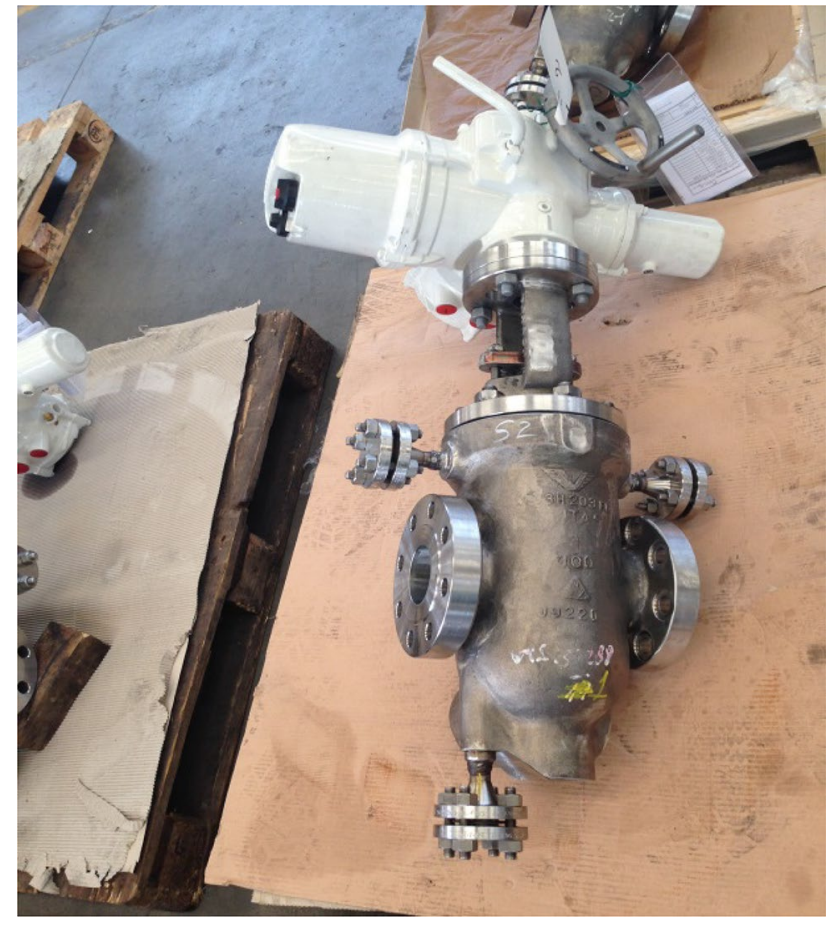

Fig. 6 Electrical actuated through conduit gate valve valve-to-actuator interface is based on ISO 5210 or 5211 standards $[6,7]$.

\subsection{Adapter fabrication}

The adapter is recommended to be fabricated as a single component rather than multiple pieces welded together. However, if the adapter supplier (usually the actuator supplier) cannot produce a one-piece adapter, then fullpenetration welds should be used rather than fillet welds for better joint efficiency. For example, an adapter can be made of a piece of pipe welded to two flanges from both sides. Finite element analysis may be done on the adapter to make sure that it withstands the loads, especially if the valve and actuator are large.

\subsection{Material}

Different choices of material are readily available such as carbon steel, austenitic stainless steel, and $22 \mathrm{Cr}$ duplex. Austenitic stainless steel 316 may be more practical for offshore applications instead of painted carbon steel. However, $22 \mathrm{Cr}$ duplex coupling provides higher mechanical strength compared to austenitic stainless steel 316 . The price of painted carbon steel coupling is almost the same as the coupling price in SS316. $22 \mathrm{Cr}$ duplex coupling has almost double price of SS316 coupling material. Table 1 compares the mechanical strength (Tensile, Yield) of $22 \mathrm{Cr}$ duplex, SS316 and carbon steel standard ASTM piping. ASTM stands for American Society for Testing and Materials.

\subsection{Drive shaft}

Requirements for drive components are given in this section. Refer to section 4.7 of API 6DX: "Coupling is a driven component (driver adapter, drive tube, drive shaft) that allows transmission of torque and/or thrust from an actuator driving component to the valve shaft/stem. Therefore, shaft and shaft extension integrity and strength have a

Table 1 Comparing carbon Steel, SS316 and 22Cr duplex mechanical strength

\begin{tabular}{lll}
\hline Material & Tensile (Ksi) & Yield (Ksi) \\
\hline Carbon steel & 60 & 35 \\
SS316 & 75 & 30 \\
22 Cr duplex & 90 & 65 \\
\hline
\end{tabular}




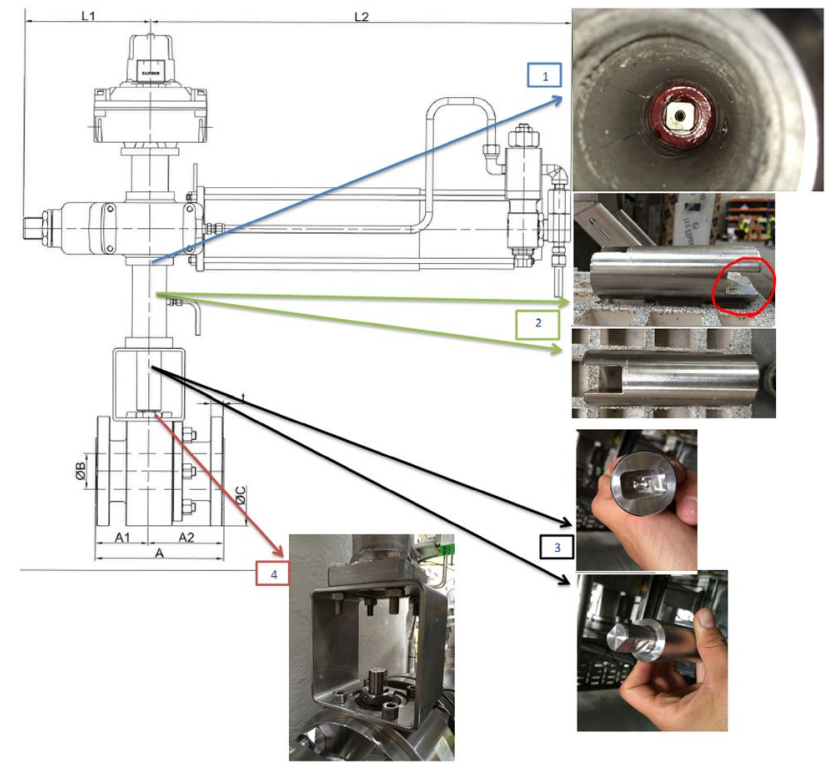

Fig. 7 Inappropriate machining between stem extension pieces

positive effect on the valve and actuator integrity". Figure 7 shows mismatching between two pieces of stem extension between the valve and actuator. These two pieces in section numbers 2 and 3 are not machined correctly at the end, so the stem extension (drive shaft) is loosely coupled between the valve and actuator. The mismatch was discovered during the final inspection of the valve at valve manufacturer factory before releasing the valve to the yard for construction and operation.

\section{Blast load calculations}

Blast load calculations evaluate the integrity between the valve and actuator due to an explosive external load in order to ensure that the valve can be operated during the explosion. The explosion load is evaluated as a force equivalent to the explosive pressure $(P)$ which is applied to the centre of gravity of the actuator area S. Equation (1) shows the explosion load calculations:

$F_{p}=$ Pdyn $\cdot C_{d} \cdot D L F \cdot S$

where $F_{p}$ : Force Equivalent to explosive pressure (Newton); Pdyn: Explosive Pressure (MPa); $C_{d}$ : Blast drag Coefficient equal to one for piping system; DLF: Dynamic load factor considered to 1.5 in this paper; and S: Area $\left(\mathrm{mm}^{2}\right)$.

Equation (1) is provided in DNV-RP-D101 [5].

The blast drag coefficient $C_{d}=1$ should be used for piping blast load calculations.

The dynamic load factor (DLF) should be in the range of 1.5 to 2.0 if no dynamic analysis or model is to be found. DLF is considered equal to 1.5 in this example.
The pressure $P$ dynamic is given equal to 0.15 Barg in this example. The actuator is a pneumatic-type cylinder with a length of $1100 \mathrm{~mm}$ and diameter of $242 \mathrm{~mm}$. The total area of the actuator is calculated using Eq. (2):

$S_{\text {total }}=D \times L$

where $S_{\text {total }}=$ Area of actuator $\left(\mathrm{mm}^{2}\right), D=$ diameter of actuator $(\mathrm{mm}), L=$ length of actuator $(\mathrm{mm})$.

$S_{\text {total }}=242 \times 1100=266200 \mathrm{~mm}^{2}$

The affected area of the actuator by blast load $\left(S_{a}\right)$ is the middle section, highlighted in Fig. 8, that makes up 10\% of the total area of the actuator. In fact, the middle section of the actuator has $20 \%$ of the actuator length and half of the actuator diameter. Therefore,

$S_{a}=10 \% \times 266200=26620 \mathrm{~mm}^{2}$

Placing the area of the actuator and other parameters into Eq. (1):

$F_{p}=0.015 \times 1 \times 1.5 \times 26620=598.95 \mathrm{~N}$

\subsection{Adapter bolting longitudinal stress calculation}

The valve is under operation during the explosion load, so the next step is to calculate the longitudinal stress due to internal pressure on the bolting connections of the adapter between the valve and actuator, $\partial_{p}$, using Eq. (3):

$\partial_{P}=P \times S_{\text {adapt }} /\left(S b_{1} \times 10\right)$

$\partial_{P}(\mathrm{MPa})=$ Longitudinal Stress due to internal pressure, $\mathrm{P}$ $(B a r)=$ maximum internal pressure, $S_{\text {adapt }}\left(\mathrm{mm}^{2}\right)=$ adaptor flange section under internal pressure, $S b_{1}\left(\mathrm{~mm}^{2}\right)=$ Section of bolting.

The equation is created and developed based on ASME pressure vessel design code. The internal pressure for a 6 " $\times 4$ " Class 300 ball valve in $22 \mathrm{Cr}$ duplex is equal to $51.7 \mathrm{Barg}$, assuming that the design temperature is a maximum of $50^{\circ} \mathrm{C}[8]$.

The adapter flange has an external diameter of $38 \mathrm{~mm}$ and an internal diameter of $28 \mathrm{~mm}$. Thus, the pressurized area (the empty area between) is calculated using Eq. (4):

$\mathrm{S}_{\text {adapt }}\left(\mathrm{mm}^{2}\right)=A=\pi r_{\text {out }}^{2}-\pi r_{\text {in }}^{2}$

$$
\begin{aligned}
S_{\text {adapt }}\left(\mathrm{mm}^{2}\right) & =3.14 \times\left(\frac{38^{2}}{4}-\frac{28^{2}}{4}\right)=3.14 \times(361-196) \\
& =3.14 \times 165=518.1 \mathrm{~mm}^{2}
\end{aligned}
$$

The adapter flange has 6 pieces M8 bolts and each has cross section of $32 \mathrm{~mm}^{2}$. Therefore, the total cross section of bolting $\mathrm{Sb}_{1}=6 \times 32=192 \mathrm{~mm}$.

Now it is possible to calculate $\partial_{p}$ using Eq. (3): 
Fig. 8 Valve and actuator sketch
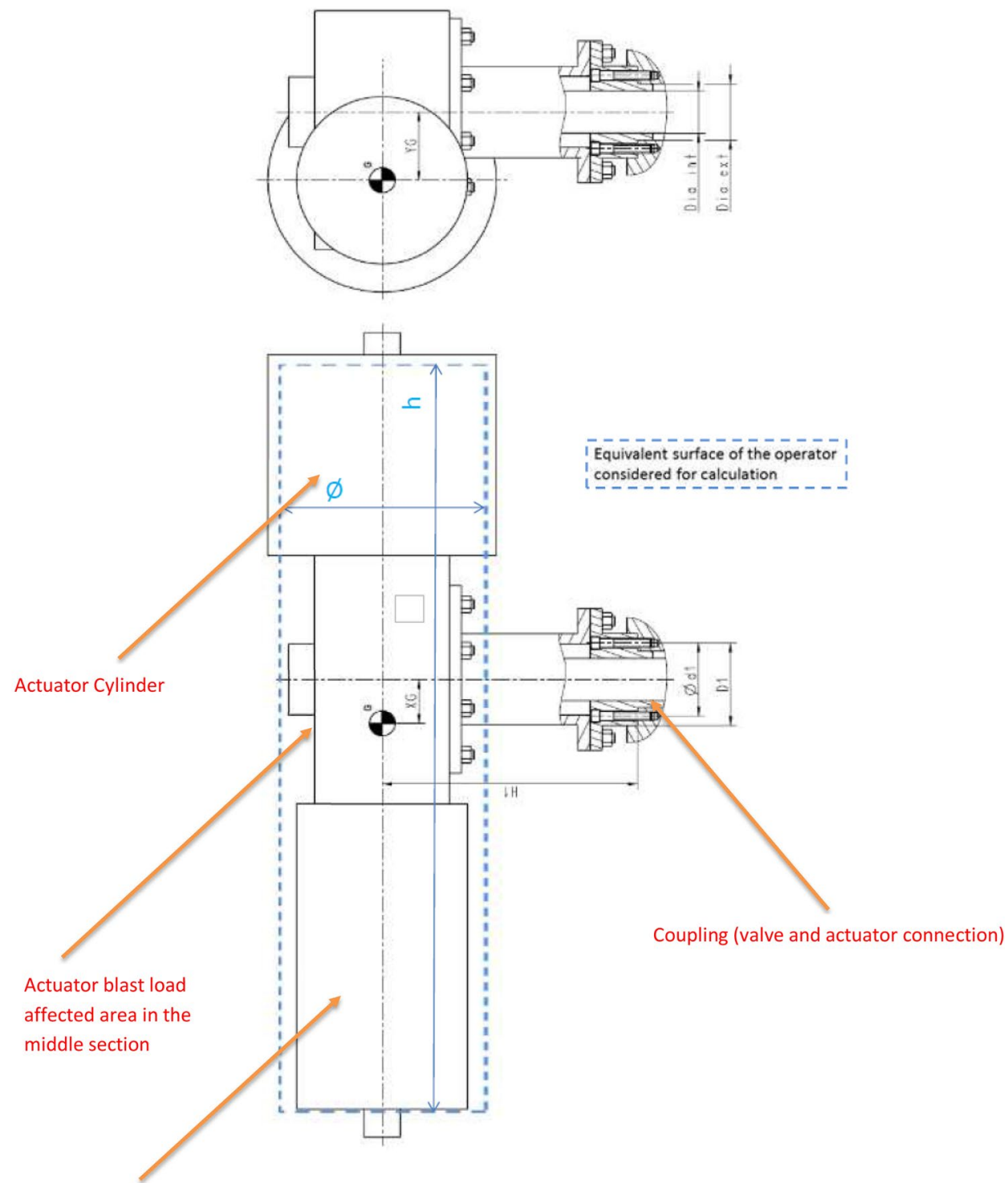

Actuator Spring (piston)

section
$\partial_{P}=51.7 \times 518.1 /(192 \times 10)=14 \mathrm{MPa}$

The next step is to calculate the bending moment $\left(M_{f 1}\right)$ that is created through the explosion force using Eq. (5):

$M_{f 1}=F_{p} \times \frac{H 1}{1000}$

$M_{f 1}=$ bending moment $(\mathrm{N} \mathrm{m}), F_{p}=$ explosive pressure force (N), $H 1=$ bending moment $\operatorname{arm}$ of $F_{p}(\mathrm{~mm})$.

$\mathrm{H} 1$ is the distance from the centre of the actuator-to-coupling bolting to the top flange, which is $300 \mathrm{~mm}$.

$M_{f 1}=5989.5 \times 300 / 1000=1797 \mathrm{~N} \mathrm{~m}$

The longitudinal stress $\partial_{1}$ is calculated using Eq. (6) developed from ASME code:
$\partial_{1}=M_{f 1} \cdot 1000 /\left(D_{1} \cdot S b_{1} / 2\right)+\partial_{P}$

$D_{1}=$ moment arm of bolting $(\mathrm{mm})=64.5 \mathrm{~mm}$

This value which is given by the valve manufacturer is shown in Fig. 8.

$\partial_{1}=1796.85 \times 1000 /(64.5 \times 192 / 2)+14=304.2 \mathrm{MPa}$

The super duplex bolting in ASTM A1082 grade UNS S32760 with the yield strength is $550 \mathrm{MPa}$ [9]. Considering a $10 \%$ safety factor, the longitudinal load on the bolt shall not exceed $90 \% \times 550=495 \mathrm{MPa}$. Since the longitudinal load $\partial_{1}$ is equal to $304.2 \mathrm{MPa}$ and less than $495 \mathrm{MPa}$, the connection between the valve and actuator is safe against 
longitudinal stresses created by blast and valve internal pressure.

\subsection{Adapter bolting shear stress calculation}

The calculation in this section demonstrates that the bolting connections between the valve and the actuator can withstand the shear stress. The adapter bolting strength validation is calculated using Eqs. (7) and (8):

$M t_{1}=\left(F_{p} \cdot X_{G} / 1000\right)+\mathrm{T}$

$M t_{1}=$ torque due to $F_{p}(\mathrm{~N} \mathrm{~m}), X_{G}=$ centre of gravity position $(\mathrm{mm})=250 \mathrm{~mm}, T=$ valve torque $(\mathrm{N} \mathrm{m})=546 \mathrm{~N} \mathrm{~m}$.

$M t_{1}=(5989.5 \times 250 / 1000)+546=2043 \mathrm{~N} \mathrm{~m}$

Shear stress is calculated using Eq. (8):

$\left.\tau_{1}=\left(F_{p} / S b_{1}\right)\right)+M t_{1} \cdot 1000 /\left(S b_{1} \cdot d_{1}\right)$

$d_{1}=64.5 \mathrm{~mm}$

$\tau_{1}=(5989.5 / 192)+(2043.375 \times 1000) /(192 \times 64.5)$

$=31.195+165=196.195 \mathrm{MPa}$

Since shear stress is less than $90 \%$ of the bolting yield, which is equal to $495 \mathrm{MPa}$, the connection between the valve and actuator is strong enough against the shear stress developed by the blast load. Figure 8 shows a sketch of the valve and actuator as well as the parameters.

\section{Conclusion}

Figure 7 shows mismatching between two pieces of stem extension between the valve and actuator. These two pieces are not machined correctly at the end, so the stem extension (drive shaft) is loosely coupled between the valve and actuator. The integrity between the valve and actuator should be strong enough to withstand different loads such as blast load without separating from each other. The integrity between the valve and actuator of a $6 " \times 4$ " Class 300 ball valve in $22 \mathrm{Cr}$ duplex material was evaluated against the blast load as well as internal pressure. Longitudinal and shear stress values were calculated and compared to the allowable stress of the bolting, which is made in $25 \mathrm{Cr}$ super duplex material. The result showed that the bolting between the valve and actuator can withstand the stresses generated from blast load. Both shear and longitudinal stresses are less than $90 \%$ of the bolting yield stress for $22 \mathrm{Cr}$ duplex, so the conclusion is that the connections between the $6 " \times 4$ " Class 300 ball valve and the pneumatic actuator are strong enough against blast loads. However, blast load is just one parameter which should be considered for integrity of the valve and actuator.

\section{Compliance with ethical standards}

Conflict of interest The author declares that there is no conflict of interest.

\section{References}

1. American Petroleum Institute (API) (2012) Standard for actuator sizing and mounting kits for pipeline valves. API 6DX, 1st edn. API, Washington, DC

2. American Petroleum Institute (API) (2014) Specification for pipeline and piping valves. API 6D, 24th edn. API, Washington, DC

3. The American Society of Mechanical Engineers (ASME) (2004) Valves-flanged, threaded, and welding end. ASME B16.34. ASME, New York

4. American Society of Testing and Materials (ASTM) (2016) Standard specification for high strength precipitation hardening and duplex stainless steel bolting for special purpose applications. ASTM A1082/A1082M. ASTM, West Conshohocken

5. Det Norske Veritas (DNV) (2008) Structural analysis of piping systems. Recommended practice DNV-RP-D101. DNV, Høvik

6. International Organization for Standardization (ISO) (2001) Industrial valves-part-turn actuator attachment. ISO 5211, 1st edn. ISO, Geneva

7. International Organization for Standardization (ISO) (2007) Pipeline transportation systems-pipeline valves. ISO 14313, 2nd edn. ISO, Geneva

8. International Organization for Standardization (ISO) (2011) Petroleum and natural gas industries-mechanical integrity and sizing of actuators and mounting kits for pipeline valves. ISO 12490, 1st edn. ISO, Geneva

9. International Organization for Standardization (ISO) (2017) Industrial valves - multi-turn actuator attachment. ISO 5210, 2nd edn. ISO, Geneva

Publisher's Note Springer Nature remains neutral with regard to jurisdictional claims in published maps and institutional affiliations. 